\title{
RNAi pathways contribute to developmental history- dependent phenotypic plasticity in C. elegans
}

\author{
SARAH E. HALL, ${ }^{1,3,4}$ GUNG-WEI CHIRN, ${ }^{2}$ NELSON C. LAU, ${ }^{2,4}$ and PIALI SENGUPTA ${ }^{1}$ \\ ${ }^{1}$ Department of Biology and National Center for Behavioral Genomics, Brandeis University, Waltham, Massachusetts 02454, USA \\ ${ }^{2}$ Department of Biology and Rosenstiel Basic Medical Science Research Center, Brandeis University, Waltham, Massachusetts 02454, USA
}

\begin{abstract}
Early environmental experiences profoundly influence adult phenotypes through complex mechanisms that are poorly understood. We previously showed that adult Caenorhabditis elegans that transiently passed through the stress-induced dauer larval stage (post-dauer adults) exhibit significant changes in gene expression profiles, chromatin states, and life history traits when compared with adults that bypassed the dauer stage (control adults). These wild-type, isogenic animals of equivalent developmental stages exhibit different signatures of molecular marks that reflect their distinct developmental trajectories. To gain insight into the mechanisms that contribute to these developmental history-dependent phenotypes, we profiled small RNAs from post-dauer and control adults by deep sequencing. RNA interference (RNAi) pathways are known to regulate genome-wide gene expression both at the chromatin and post-transcriptional level. By quantifying changes in endogenous small interfering RNA (endo-siRNA) levels in post-dauer as compared with control animals, our analyses identified a subset of genes that are likely targets of developmental history-dependent reprogramming through a complex RNAi-mediated mechanism. Mutations in specific endo-siRNA pathways affect expected gene expression and chromatin state changes for a subset of genes in post-dauer animals, as well as disrupt their increased brood size phenotype. We also find that both chromatin state and endo-siRNA distribution in dauers are unique, and suggest that remodeling in dauers provides a template for the subsequent establishment of adult post-dauer profiles. Our results indicate a role for endo-siRNA pathways as a contributing mechanism to early experience-dependent phenotypic plasticity in adults, and describe how developmental history can program adult physiology and behavior via epigenetic mechanisms.
\end{abstract}

Keywords: RNAi; siRNA; C. elegans; dauer; chromatin; gene expression

\section{INTRODUCTION}

The experience of an organism during early development plays an important role in regulating its adult phenotype. For instance, increasing evidence suggests that nutrition or diet experienced during fetal or early post-natal development has long-lasting effects on adult feeding behavior and physiology (Fernandez-Twinn and Ozanne 2010; Tamashiro and Moran 2010; Rinaudo and Wang 2012). Although changes in the epigenome have been correlated with the effects of early experience on adult behaviors (Weaver et al. 2004; Bale et al. 2010; Caldji et al. 2011), the mechanisms by which developmental history modulates adult phenotypes remain unclear.

Early experience also modulates adult behaviors in the nematode Caenorhabditis elegans, and recent studies suggest

${ }^{3}$ Present address: Department of Biology, Syracuse University, Syracuse, NY 13244, USA

${ }^{4}$ Corresponding authors

E-mail shall@syr.edu

E-mail nlau@brandeis.edu

Article published online ahead of print. Article and publication date are at http://www.rnajournal.org/cgi/doi/10.1261/rna.036418.112. that a subset of these effects can be transmitted to descendants (Rose et al. 2005; Ebrahimi and Rankin 2007; Hall et al. 2010; Remy 2010; Harvey and Orbidans 2011). Environmental cues experienced during early larval stages regulate a particularly critical developmental decision in C. elegans. High concentrations of a complex mix of small molecules called dauer pheromone, high temperatures, and low food availability assessed during early L1 larval stages trigger entry of L2 larvae into the stress-resistant and nonaging dauer developmental stage (Golden and Riddle 1982, 1984). Upon improvement of environmental conditions, $C$. elegans emerges from the dauer stage to resume reproductive growth. We previously showed that wild-type post-dauer adult animals exhibit markedly distinct phenotypes from adult animals that bypassed the dauer stage (henceforth referred to as "control" animals) (Hall et al. 2010), suggesting that C. elegans retains a cellular memory of its developmental history. Post-dauer animals exhibited a longer mean lifespan and produced more progeny than control animals (Hall et al. 2010). Moreover, the expression of $\sim 2000$ genes, as well as genome-wide levels of examined histone modification levels, were significantly altered upon passage through the dauer 
stage (Hall et al. 2010). Mutations in chromatin modifier genes eliminated the increased brood size and a subset of the gene expression changes in post-dauer animals (Hall et al. 2010), suggesting that changes in the chromatin state may, in part, underlie the establishment or maintenance of a memory of developmental trajectory.

Small RNA (sRNA) pathways are known to globally regulate gene expression and chromatin states. C. elegans possesses a complex array of sRNA pathways, including 26 different Argonaute (AGO)-class proteins that mediate diverse functions (Yigit et al. 2006; Boisvert and Simard 2008; van Wolfswinkel and Ketting 2010; Fischer et al. 2011; Ketting 2011). MicroRNAs (miRNAs) act primarily via post-transcriptional mechanisms to promote mRNA degradation and translational inhibition (Bartel 2009; Brodersen and Voinnet 2009; Carthew and Sontheimer 2009). In addition, the germline-specific 21U-RNAs silence transposons, although their complete functions are not yet fully characterized (Ruby et al. 2006; Batista et al. 2008; Das et al. 2008; Wang and Reinke 2008; Bagijn et al. 2012). The most abundant class of sRNAs in adults are the small interfering RNAs (siRNAs) that have been directly implicated as epigenetic factors that maintain genome and germline integrity via modifications to the chromatin state and regulation of transcriptional silencing of repetitive elements in diverse organisms including in C. elegans (for recent reviews, see Moazed 2009; Bourc'his and Voinnet 2010; Grewal 2010; van Wolfswinkel and Ketting 2010; Ketting 2011; Lejeune and Allshire 2011).

In C. elegans, two subclasses of endogenous siRNAs (endosiRNAs) are 26 and 22 nucleotides in length with $5^{\prime}$ terminal G nucleotides (26G-RNAs and 22G-RNAs, respectively), are antisense to coding transcripts, and have been implicated in regulating fertility and embryogenesis via regulation of gene expression and chromatin modifications (Lee et al. 2006; Aoki et al. 2007; Pak and Fire 2007; Grishok et al. 2008; Claycomb et al. 2009; Gu et al. 2009; Han et al. 2009; Conine et al. 2010; Gent et al. 2010; Guang et al. 2010; Vasale et al. 2010; Zhang et al. 2011). 26G-RNAs are primary siRNAs with a $5^{\prime}$ monophosphate derived from Dicer processing, while 22G-RNAs are secondary siRNAs with a $5^{\prime}$ triphosphate dependent on RNA-dependent RNA polymerases (RdRPs) for biogenesis (Lau et al. 2001; Fischer 2010). Genetic analyses of various siRNA-pathway mutants suggest that these subclasses of endo-siRNAs and their targeted genes operate in partly overlapping pathways. For example, 26GRNAs require the RRF-3 RdRP for their biogenesis (Han et al. 2009; Vasale et al. 2010), and interact either with the AGO protein ERGO-1 in somatic cells and oocytes (Han et al. 2009; Gent et al. 2010; Vasale et al. 2010), or with the AGO proteins ALG-3/4 in sperm (Han et al. 2009; Conine et al. 2010). In contrast, the more abundant 22G-RNA class requires the RdRPs EGO-1 or RRF-1 (Claycomb et al. 2009; Vasale et al. 2010) and regulates gene expression and transposon silencing in the germline via worm-specific AGO proteins
(WAGO class) (Gu et al. 2009), or regulates chromatin structure and chromosome segregation both in the germline and soma via the AGO protein CSR-1 (Claycomb et al. 2009). In somatic cells, 22G-RNAs also associate with the AGO protein NRDE-3 that re-enters the nucleus in a siRNA-bound state and targets nascent RNAs to regulate histone $\mathrm{H} 3 \mathrm{~K} 9$ methylation (Guang et al. 2008, 2010; Burkhart et al. 2011). In addition, genes such as mut-16 act in both 22G- and 26G-sRNA pathways in the germline and soma (Zhang et al. 2011). An additional layer of complexity involves the stability and regulation of sRNAs. Recent reports have shown that 22GsiRNAs are targeted for destruction by CDE-1 uridylase (van Wolfswinkel et al. 2009), 26G- and 21U-sRNAs are stabilized after methylation by HENN-1 (Billi et al. 2012; Montgomery et al. 2012), and 21U-siRNAs may play a role in mediating germline gene silencing to distinguish "self" from "non-self" elements (Ashe et al. 2012; Shirayama et al. 2012). Although much is now known about the diversity of these endo-siRNA pathways, how these pathways are regulated biologically in response to environmental cues remains largely uncharacterized.

Given the complexity of gene expression and chromatin state changes as a function of developmental history, we sought to examine the contribution of RNAi pathways to early experience-dependent regulation of adult phenotypes in $C$. elegans. Our profiling of sRNAs from control and post-dauer adults reveals hundreds of genes with significant changes in endo-siRNAs associated with distinct endo-siRNA pathways, a subset of which also exhibits changes in gene expression. We demonstrate that mutations in specific endo-siRNA pathway factors disrupt expected gene expression changes in post-dauer animals for a subset of these genes, and also affect the increased brood size phenotype of post-dauer adults. Moreover, we show that the CSR-1 AGO pathway contributes to the chromatin state changes observed in post-dauer animals. Our results suggest that endo-siRNA pathways act as a potential mechanism for a subset of the long-term effects of early experience, and contribute to plasticity in adult phenotypes as a consequence of different developmental histories.

\section{RESULTS}

\section{sRNA profiles of control and post-dauer animals}

To examine whether the developmental trajectory of the dauer stage affects the regulation of RNAi pathways, we performed deep sequencing of sRNA libraries cloned from two biological replicates of control and post-dauer adult populations, as well as dauer and L3 larval stages. In all cases, growth, as well as entry into and exit from the dauer stage were tightly synchronized (Hall et al. 2010). sRNAs were collected from 1-d-old adult control animals that bypassed the dauer stage, and from post-dauer populations $2 \mathrm{~d}$ following exit from the dauer stage in which they had remained for $24 \mathrm{~h}$. Libraries were constructed so as to capture all sRNA species, and 
sequenced on the Illumina platform. Reads that mapped to the $C$. elegans genome were categorized based on their predicted genomic annotation (Fig. 1A; Supplemental Table S1).

The overall percentages of each category of sRNA represented in the reads in the adult libraries were grossly similar regardless of developmental history, although there were some differences between the biologically independent replicate libraries (Fig. 1A; Supplemental Fig. S1), perhaps due to slight differences in growth conditions or library construction. Despite this variability, we calculated an overall positive Spearman rank rho-value that indicates positive correlation of sRNA count changes between the two replicates (Supplemental Fig. S1), indicating that a subset of sRNAs exhibited consistent differences in abundance levels when compared between control and post-dauer libraries within the replicates $(P<0.05)$.

Previous analyses have shown that miRNA expression is altered by developmental trajectory (Karp et al. 2011); our analyses of miRNAs suggested results consistent with these reports (see Supplemental text; Supplemental Fig. S2). We focused the remainder of this study on endo-siRNAs, which in C. elegans are generally germline enriched but are also present in the soma (Gu et al. 2009; Han et al. 2009). We first mapped all siRNAs to the genome to identify the subset with sequences antisense to coding sequences, and then expanded the search to include siRNAs against corresponding $5^{\prime}$ UTR and 3' UTR regulatory regions. siRNAs mapping to

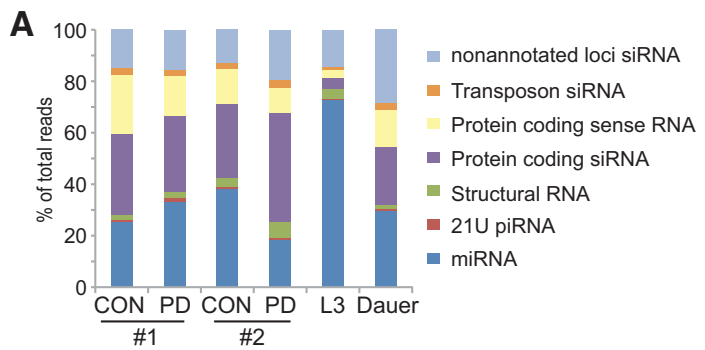

B
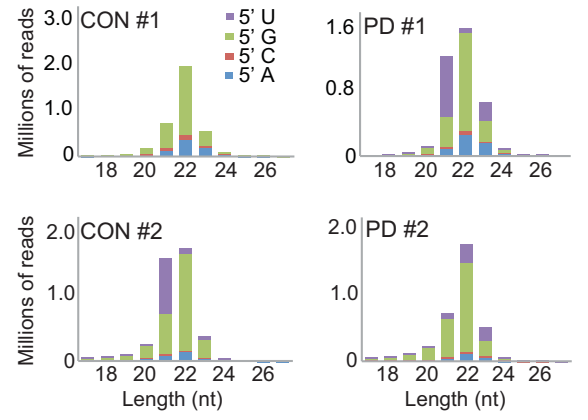

FIGURE 1. Endogenous small RNA populations from animals at different life stages and with distinct developmental histories. (A) Percentage of total reads in each indicated category that matched genomic sequences. CON and PD \#1 and \#2 refer to biological replicate libraries (see Materials and Methods). (B) Distribution of endo-siRNAs by nucleotide length and identity of the $5^{\prime}$ nucleotide for sequenced adult library. Note different $y$-axes in different panels. endogenous transposons were not included in this category, because our analyses suggested that their levels were not altered in post-dauer animals (Fig. 1A; data not shown). Given the diversity of different endo-siRNAs in C. elegans (Fischer 2010; Ketting 2011), we further examined the distribution of different endo-siRNA classes in the different libraries. The bulk composition of endo-siRNAs in control and post-dauer libraries was not consistently different between replicate libraries (Fig. 1B; Supplemental Fig. S1B), indicating that global levels of endo-siRNA populations are similar between control and post-dauer animals.

\section{Specific siRNA pathways are associated with changes in siRNA abundance in post-dauer animals}

Although global levels of siRNA populations were similar between control and post-dauer adult populations, specific distributions of these molecules across the genome could nevertheless be regulated by developmental history. To address this possibility, we first determined whether siRNA populations that are antisense to individual coding, $5^{\prime}$ UTR or $3^{\prime}$ UTR regions showed different levels in control and post-dauer animals. Considering only genes for which the siRNA read coverage was $\geq 10$ reads per million ( $\mathrm{rpm}$ ) in at least one of the profiled libraries, we identified 6476, 727, and 929 genes with significant siRNA abundance in the coding regions, 5' UTR or 3' UTR regulatory regions, respectively (Fig. 2A,B). We observed a total of 286 and 197 genes that exhibited $>1.5$-fold increase or decrease, respectively, in associated siRNA levels mapping to coding regions in post-dauer libraries as compared with their corresponding control libraries in both biological replicates (Fig. 2A, red dots; Fig. 2B; Supplemental Fig. S1B, yellow cells; Supplemental Table S2). Similarly, we identified 69 and 27 genes that exhibited $>1.5$-fold increase or decrease, respectively, of mapped siRNAs in 5' UTR sequences (Fig. 2B; Supplemental Table S2). In addition, 102 and 34 genes exhibited $>1.5$ increase or decrease, respectively, of siRNAs in $3^{\prime}$ UTR regulatory sequences (Fig. 2B; Supplemental Table S2). Interestingly, although $17 \%$ of genes with siRNAs present $(329+583+223$ +14 genes) contain siRNAs in more than one region, only $3 \%$ of genes that exhibit siRNA level changes $(11+11+2$ genes) have changes in more than one region (Fig. 2Bi,ii). This observation suggests that distinct transcriptional and posttranscriptional mechanisms may mediate gene regulation due to developmental history (Fig. 2B).

We further investigated whether genes exhibiting altered levels of siRNAs in post-dauer adults were preferentially targeted by specific siRNA pathways. We focused our analysis on genes with changes in siRNA levels localized to the coding region in order to perform a meta-analysis of these gene sets together with previously published gene sets shown to be targets of different proteins such as AGOs and RdRPs. We found that more genes exhibiting increased siRNA levels in postdauer animals were targets of the CSR-1 and EGO-1 pathways 
A
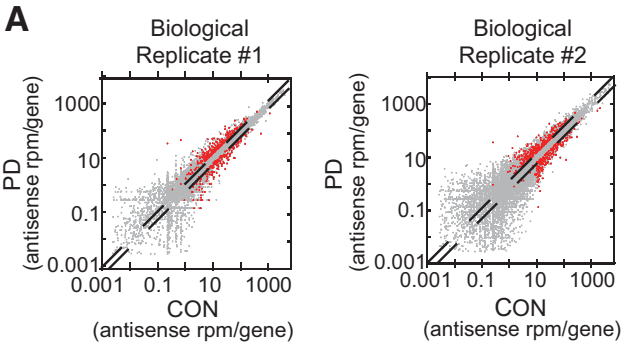

$\mathrm{Bi}$

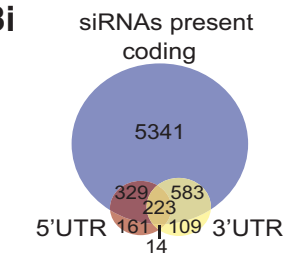

C

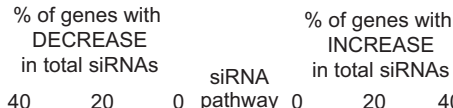
\begin{tabular}{rrrrr}
$40 \quad 20$ & 0 pathway 0,20 & 40 \\
\hline 48 Unknown & Unk &
\end{tabular} 75 26G $\quad$ I 52 \begin{tabular}{l|l|l}
30 & ALG-3/4 & 2
\end{tabular}

15 I CSR-1 91

6 I| ERGO-1 | 2
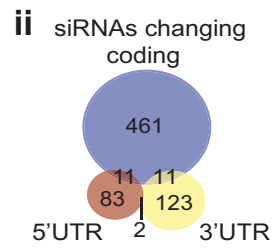

5I NRDE-3 I

19 EGO-1 $\quad$ - 55

MUT-16

FIGURE 2. A subset of genes with expression differences between postdauer and control adults exhibit significant changes in endo-siRNA levels. (A) Scatter plots showing the normalized number of siRNA reads mapping antisense to every gene for control and post-dauer libraries in each of the biological replicates. sRNA reads mapping to coding regions were normalized to the total number of reads per library (reads per million or $\mathrm{rpm}$ ). Genes with $>10 \mathrm{rpm}$ and $>1.5$-fold changes in siRNA levels in both replicates are considered significant (highlighted in red). Genes not meeting these criteria are represented in gray. Dashed lines show 1.5-fold cutoff for significance. The overall association of genes displaying siRNA changes is positively correlated between the two replicates (Supplemental Fig. S1). (B,i) The Venn diagram shows numbers of genes with significant levels of siRNAs mapping to coding, $5^{\prime}$ UTR, and $3^{\prime}$ UTR regions. ( $B$,ii) The Venn diagram indicates the numbers of genes with significant changes in siRNA levels comparing control and post-dauer libraries in their corresponding coding, $5^{\prime}$ UTR, and $3^{\prime}$ UTR regions. (C) The percentage of genes showing up-regulation, down-regulation, or no change in gene expression between control and post-dauer adults (Hall et al. 2010) that are targets of predicted siRNA pathways. Total numbers of genes represented by each bar are indicated.

associated with 22G-RNAs (91 and 55 genes, respectively, in the up-regulated set) (Fig. 2C; Aoki et al. 2007; Claycomb et al. 2009; Gu et al. 2009; van Wolfswinkel et al. 2009; Vasale et al. 2010; Maniar and Fire 2011) than genes with decreased siRNA levels (15 and 19 genes, respectively, in the down-regulated set) (Fig. 2C). In contrast, more genes exhibiting decreased siRNA levels were targets of 26G-RNAs (52 and 74 genes in the up- and down-regulated sets, respectively) (Fig. 2C; Han et al. 2009; Conine et al. 2010; Zhang et al.
2011). We also noted that 145 genes with changes in siRNA levels have not been reported to be predicted targets of any known siRNA pathway (Fig. 2C), suggesting that an as yet uncharacterized AGO protein may play a role. These observations suggest that early environmental and developmental histories can modulate endogenous siRNA pathways in wildtype adults.

\section{Changes in siRNA abundance correlate with changes in expression of a subset of genes upon passage through the dauer stage}

Next, we examined the relationship between changes in siRNA abundance and gene expression changes previously observed between control and post-dauer adults (Hall et al. 2010). A majority of genes showing changes in siRNA levels mapping to their coding regions did not exhibit changes in gene expression in post-dauer animals (Fig. 2C, gray bars; Supplemental Table S3; see below), suggesting that alteration of siRNA levels in post-dauer animals may be playing additional regulatory roles (Claycomb et al. 2009). However, 77 genes exhibited changes in both coding region siRNAs and gene expression levels in post-dauer animals (Fig. 2C, green and red bars; Supplemental Table S3). Using a $\mathrm{X}^{2}$ goodnessof-fit test, we determined that the number of genes in the set exhibiting both gene expression and siRNA level changes is significantly greater than that expected from random chance alone, and may reflect a biological response due to passage through the dauer stage (Supplemental Table S4). Of these genes, we noted that 28 genes whose expression is down-regulated in post-dauer animals also exhibited a significant decrease in coding region siRNA levels, and are enriched for targets of 26G-RNAs (Fig. 2C, green bars; Supplemental Fig. S3C; Supplemental Table S3). Additionally, 21 genes with up-regulated gene expression levels in post-dauer adults compared with controls also exhibit an increase in siRNA abundance in their coding regions and are primarily targeted by CSR-1 and MUT-16 pathways (Fig. 2C, red bars; Supplemental Fig. S3B; Supplemental Table S3). Using sensitive RNA probes, we verified that the siRNA abundance changes observed for two genes by deep sequencing was also detected by Northern blot (see Supplemental text; Supplemental Fig. S3D). A canonical view of RNAi is that endo-siRNA levels are negatively correlated with and/or are causal to gene expression changes (Czech et al. 2008; Ghildiyal et al. 2008; Kawamura et al. 2008; Okamura and Lai 2008; Tam et al. 2008; Watanabe et al. 2008; Gu et al. 2009; Han et al. 2009; Maniar and Fire 2011). Although 28 genes indeed displayed negatively correlated siRNA abundance changes with gene expression changes upon transient passage through the dauer stage, our data also highlight a group of genes where the siRNA and gene expression changes are positively correlated in post-dauer animals, suggesting a noncanonical mode of RNAi-mediated regulation (see below). 


\section{Functional RNAi pathways are required for changes in gene expression between control and post-dauer adult animals}

Since our analyses indentified 77 genes that exhibited changes in both coding-region siRNA abundance and gene expression levels in post-dauer animals (Fig. 2C), we next asked whether changes in transcript levels are dependent on the specific RNAi factors that modulate these sRNAs. Thus, we examined changes in gene expression in animals mutant for the 22GRNA-binding AGO csr-1 gene (Aoki et al. 2007; Claycomb et al. 2009), the 26G-RNA RdRP rrf-3 gene (Simmer et al. 2002; Han et al. 2009; Vasale et al. 2010), and the mutator protein-encoding gene mut-16 that is required for modulation of both WAGO-class 22G- and ERGO-1-class 26GRNAs, and somatic and germline RNAi (Zhang et al. 2011). For two genes, we also examined expression levels in a mago 12 strain, which carries mutations in 12 worm-specific Argonaute genes (Gu et al. 2009). csr-1 null mutations result in sterility (Yigit et al. 2006); therefore, we used a strain in which $c s r-1$ functions were rescued in the germline (henceforth referred to as $c s r-1$ hypomorph) resulting in partial rescue of the sterility phenotype (Claycomb et al. 2009).

We arbitrarily chose a set of genes from the two categories that show positively or negatively correlated changes in gene expression and siRNA abundance, as well as different gene expression patterns, and examined them in the csr-1, mut-16, rrf-3, and mago-12 mutant backgrounds (Fig. 3). The polycomb repressor complex homolog gene spat-3 and neuron enriched gene K09E9.3 both show up-regulated gene expression and decreased siRNA levels in post-dauer animals compared with controls (negatively correlated) (Fig. 3; Supplemental Fig. S4). In contrast, the c-lectin family member clec-12 and sperm-enriched gene Y43F8C.9 show either an increase or decrease in both gene expression and siRNA levels, respectively (positively correlated) (Fig. 3; Supplemental Fig. S4). Finally, we examined the actin act-2 gene and ribosomal gene rps-1 as controls, since they do not show changes
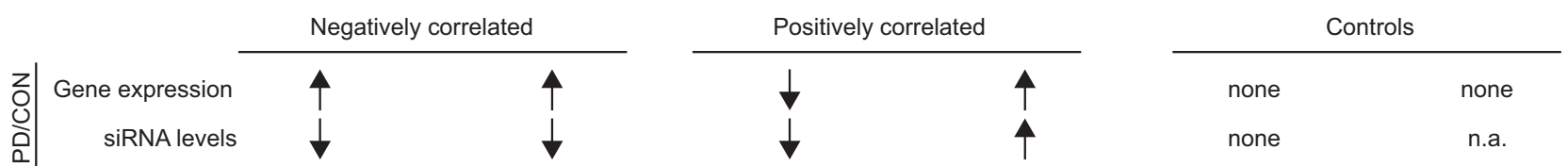

A
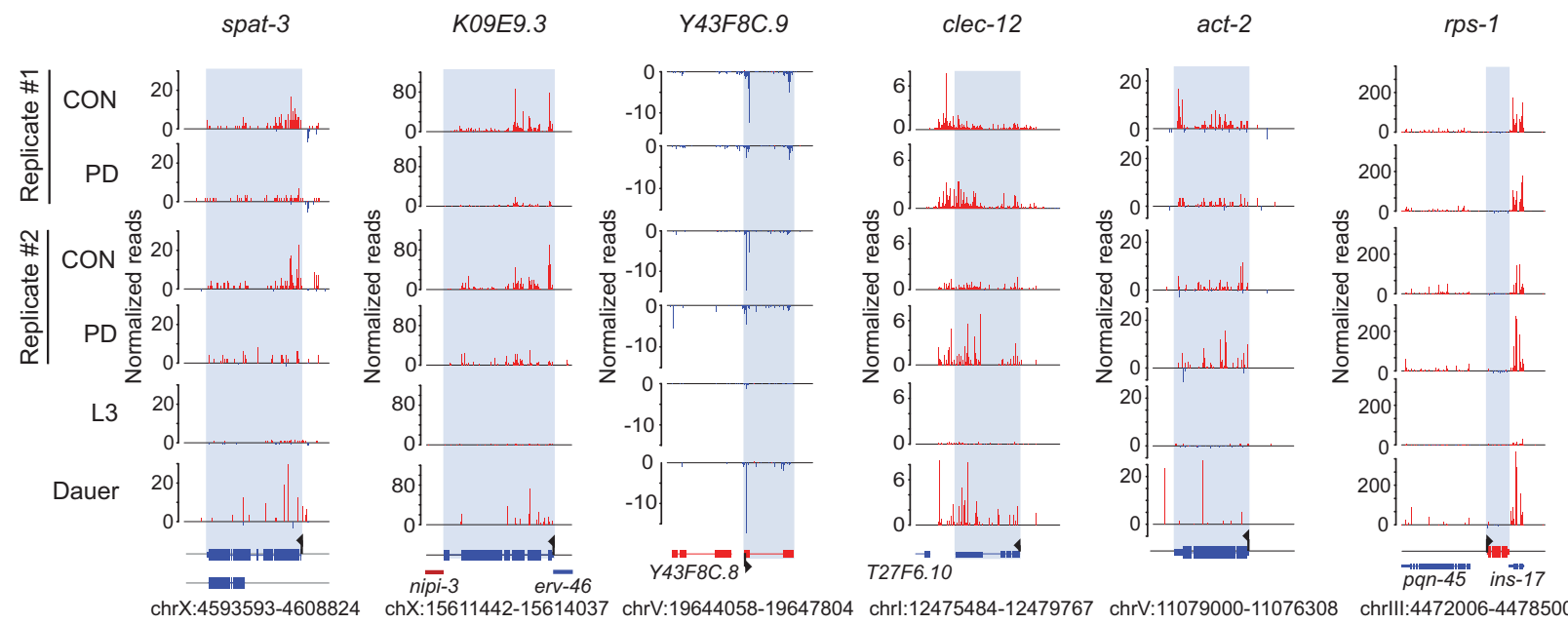

B
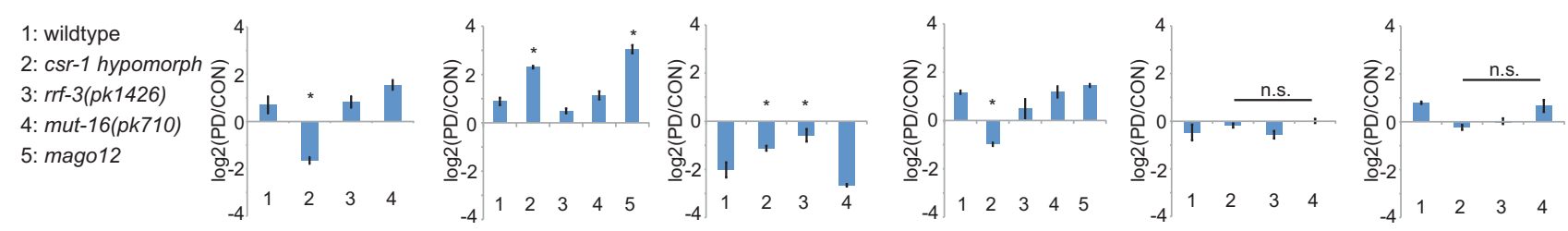

FIGURE 3. Correlation of changes in siRNA and gene expression levels in endo-siRNA pathways. (A) Plots showing normalized numbers of siRNA reads from each sequenced library for the genomic regions surrounding the indicated genes. Gene models are represented at the bottom; siRNAs overlapping with the gene-coding region are shaded in light-blue rectangles. Note different $y$-axes in different panels. Number of total and 22G-siRNAs for these regions are shown in Supplemental Figure S4. (B) The log2 ratio of expression levels in post-dauer to control adults in wild-type, germline-rescued csr-1 (Claycomb et al. 2009), rrf-3 (pk1426), mut-16 (pk710), and mago12 (Gu et al. 2009) mutant animals. Averages represent data from three independent reactions from two biological replicates. Error bars represent propagated standard deviation. (*) Different from wild-type at $P<0.05$ via one-way ANOVA with Fisher's LSD post hoc correction for multiple comparisons. (n.s.) not significant. Expression levels in control and post-dauer adults are shown in Supplemental Figure S4. 
in gene expression between wild-type control and post-dauer animals and have unaltered or undetectable siRNA levels mapping to their coding regions, respectively (Fig. 3; Supplemental Fig. S4) (Hall et al. 2010).

Our results indicate that the AGO protein CSR-1 plays a major role in the regulation of gene expression changes in wild-type post-dauer animals. 22G-siRNA bound CSR-1 targets complementary nascent RNAs in the nucleus to establish and maintain a euchromatic chromatin region in the targeted area (Claycomb et al. 2009). However, the subset of genes targeted by CSR-1 complexes is only partially overlapping with the set of genes with depleted 22G-siRNAs in a csr-1 mutant, suggesting CSR-1 has multiple roles in C. elegans RNAi pathways (Claycomb et al. 2009) (see further below). Of the genes whose expression was examined, spat-3, K09E9.3, and clec-12 previously showed a decrease in 22G-siRNAs in a csr-1 mutant background (Claycomb et al. 2009), and all showed significant changes in the ratio of gene expression levels in post-dauer compared with control animals ( $\mathrm{PD} / \mathrm{CON})$ in the $c s r-1$ hypomorph strain compared with wild-type (Fig. 3B). Interestingly, Y43F8C.9 also showed a significant change in $\mathrm{PD} / \mathrm{CON}$ expression levels in a csr-1 hypomorph, despite not being a known target of CSR-1 complexes (Fig. 3B). However, this gene is located within a chromosomal domain densely populated with CSR-1 target genes (Claycomb et al. 2009), and may be sensitive to changes in the chromatin structure affecting gene expression in csr-1 mutants (see Discussion). We found 282 additional genes that showed substantial effects on $\mathrm{PD} / \mathrm{CON}$ expression levels in $c s r-1$ hypomorph compared with wild-type via microarray analyses (Supplemental Fig. S5A; see Supplemental text). The act- 2 and $r p s-1$ control genes did not show a significant change in $\mathrm{PD} / \mathrm{CON}$ expression in the $c s r-1$ hypomorph similar to wild type (Fig. 3B), even though act-2 is a target of CSR-1 complexes (Claycomb et al. 2009). These results indicate that a functional CSR-1 AGO protein is required for changes in $\mathrm{PD} / \mathrm{CON}$ gene expression in a subset of genes, regardless of whether the corresponding siRNA changes are negatively or positively correlated.

In comparison to the requirement for CSR-1, the requirement of other examined components of the siRNA pathways in the regulation of $\mathrm{PD} / \mathrm{CON}$ gene expression changes was more gene specific. Of the examined genes, only Y43F8C.9 is a target of sperm-specific ALG-3/4, which associates with 26G-siRNAs generated by RdRP RRF-3 (Conine et al. 2010). Consistent with this, only Y43F8C.9 showed a significant change in $\mathrm{PD} / \mathrm{CON}$ expression in $r r f-3$ mutants compared with wild-type (Fig. 3B), suggesting that the $26 \mathrm{G}$ ALG-3/4 pathway plays a role in executing the change in expression due to passage through the dauer stage. However, although both K09E9.3 and clec-12 are predicted targets of MAGO12, only K09E9.3 exhibited a significant change in $\mathrm{PD} / \mathrm{CON}$ expression levels from wild type in the mago $12 \mathrm{mu}-$ tant strain (Fig. 3B; Gu et al. 2009). Similarly, although MUT-16 is predicted to target spat-3, K09E9.3, clec-12, and
Y43F8C.9, none of these genes exhibited significantly altered $\mathrm{PD} / \mathrm{CON}$ gene expression differences between mut-16 and wild-type strains (Fig. 3B). As predicted, mago12, rrf-3, and mut-16 mutant strains also did not significantly affect the $\mathrm{PD} / \mathrm{CON}$ expression levels of the control genes act-2 and rps-1 (Fig. 3B). Together, these results indicate that functional endo-siRNA pathways, and in particular, CSR-1, are necessary for changes in $\mathrm{PD} / \mathrm{CON}$ expression levels in wild-type animals for a subset of genes.

\section{Specific altered chromatin states in post-dauer animals require the AGO protein CSR-1}

Given the complexity of the siRNA-dependent changes in $\mathrm{PD} / \mathrm{CON}$ gene expression, and the prominent role of CSR1 in this process (Fig. 3; Supplemental Fig. S5A,B), we looked for a link between RNAi pathways and chromatin signatures in the post-dauer development trajectory. Our meta-analysis indicated that predicted CSR-1 targets overlapped extensively with the set of $\sim 4000$ of the highest expressed genes identified in our previous transcriptional profiling analyses (Hall et al. 2010 ), such that $75 \%$ of these genes are predicted targets of CSR-1 (Fig. 4A). Therefore, we tested whether CSR-1 plays a role in the observed changes in chromatin modifications upon passage through the dauer stage.

A chromatin regulatory role for CSR-1 is supported by its direct interaction with euchromatic regions enriched for histone $\mathrm{H} 3 \mathrm{~K} 4 \mathrm{me} 2$ and $\mathrm{H} 3 \mathrm{~K} 4 \mathrm{me} 3$ modifications in a $22 \mathrm{G}$ siRNA-dependent manner (van Wolfswinkel and Ketting 2010). In addition, csr- 1 mutants that are depleted of $22 \mathrm{G}-$ RNAs associated with transcribed protein-coding genes surprisingly display only modest changes in gene expression levels, but have a strong defect in accurate chromosome segregation (Claycomb et al. 2009; van Wolfswinkel and Ketting 2010). We previously showed that genome-wide levels of histone H3K4me3 and histone H4panAc modifications are decreased upon passage through the dauer stage and that the extent of the decrease across regulatory and coding sequences is largest for the set of genes exhibiting the highest levels of expression (Hall et al. 2010).

In our focused gene set analysis, act-2 and rps-1 are present in the set of highest-expressed genes, whereas spat-3 and K09E9.3 are expressed at lower levels. Detailed analyses of the act-2 and rps-1 genomic loci indicated that several loci neighboring the act-2 locus are in the set of highest-expressed genes, and many of these genes including act-2 are targets of CSR-1-associated 22G-RNAs (Fig. 4Bi). Similarly, the rps-1 locus is also located in a genomic region that contains highest-expressed genes (Fig. 4Bii). Although the rps-1 locus itself is not enriched for CSR-1-interacting 22G-RNAs, and indeed has few siRNAs mapped to its coding sequences (Figs. 3A, 4Bii), genes flanking $r p s-1$ are themselves predicted targets of CSR-1-associated siRNAs (Fig. 4Bii). These observations suggest that act-2 and $r p s-1$ are likely located within a larger CSR-1-targeted domain. In contrast, CSR-1 targets spat-3 
A

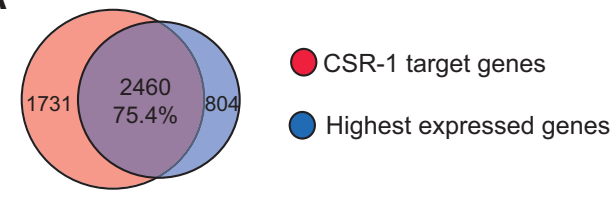

Bi

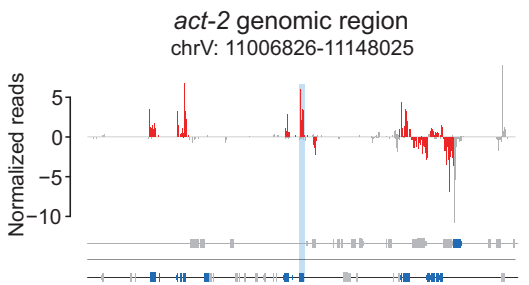

ii

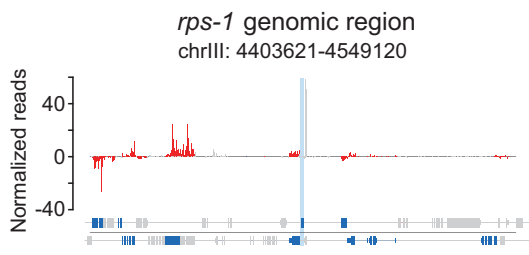

iii

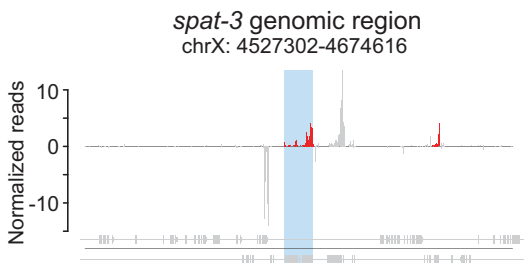

iv

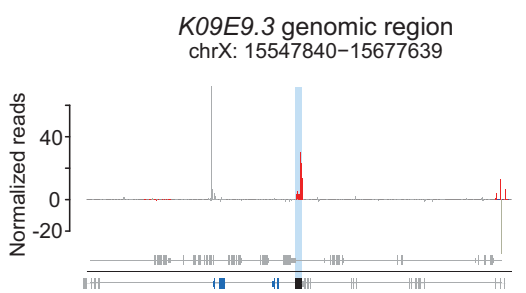

Ci

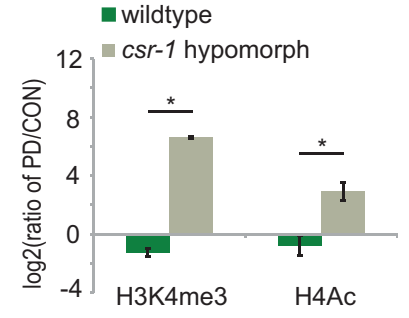

ii

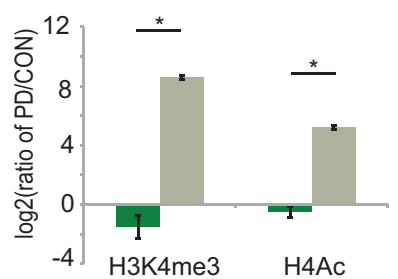

iii

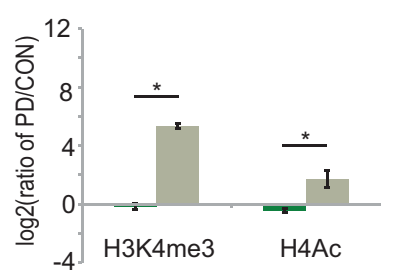

iv

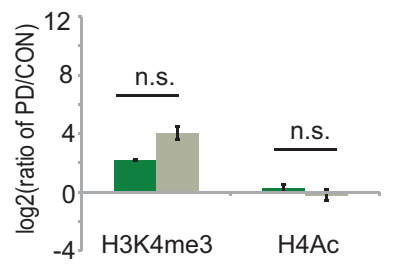

FIGURE 4. Gene expression changes and genome-wide chromatin state may be modulated by CSR-1 function. (A) Venn diagram representing the overlap of CSR-1 targets (red) (Claycomb et al. 2009) with the highest expressed genes in C. elegans control adults (blue) (Hall et al. 2010). (B) Plots showing normalized number of siRNA reads for chromosomal regions containing (i) act-2, (ii) rps-1, (iii) spat-3, and (iv) K09E9.3. Shown are siRNAs mapping to CSR-1 target genes on the plus strand (red). Gene models indicate transcripts on the plus and minus strand; genes in the highest expressed category are highlighted in blue. Coding regions of act-2, rps-1, spat-3, and K09E9.3 are highlighted by blue rectangles. Genes that are not in the highest expressed gene category are indicated in gray. Note different $y$-axes in different panels. $(C)$ Log2-transformed ratios of normalized post-dauer to control levels of the indicated histone modifications across a 100-bp sequence in the regulatory regions of each gene in wild-type and csr-1 hypomorph strains quantified via ChIP-qPCR. (*) Different from wild type for a given strain at $P<0.05$ via one-way ANOVA and Fisher's LSD post hoc correction for multiple comparisons. Averages are from three technical replicates. Histone modification levels in control and post-dauer samples from wild-type and csr-1 hypomorph strains are shown in Supplemental Figure S5.

and the MAGO12 target K09E9.3 are located in regions that are not as enriched for genes in the highest-expressed category or in CSR-1 targets (Fig. 4Biii, iv).

We examined levels of H3K4me3 and H4panAc modifications at the act-2, rps-1, spat-3, and K09E9.3 loci in wild-type and $c s r-1$ hypomorph control and post-dauer adults via chro- matin immunoprecipitation (ChIP), followed by quantitative PCR (qPCR). Higher levels of histone H3K4me3 were present at examined act-2 and rps-1 loci than at spat-3 and K09E9.3 sequences in wild-type control animals correlated with their expression levels (Supplemental Fig. S5C-F). Passage through the dauer stage resulted in lower levels of both histone modifications at act- 2 and rps- 1 sequences in postdauer animals compared with control animals (Fig. 4C). Consistent with the previously proposed role for CSR-1 in interacting with histone $\mathrm{H} 3 \mathrm{~K} 4 \mathrm{me} 3$ to maintain euchromatin domains (Claycomb et al. 2009; She et al. 2009), partial loss of CSR-1 resulted in decreased levels of histone $\mathrm{H} 3 \mathrm{~K} 4 \mathrm{me} 3$ at all examined loci in csr-1 hypomorph control animals (Supplemental Fig. S5C,D). However, we found that levels of both histone H3K4me3 and H4Ac modifications at both act-2 and rps-1 loci were greatly increased in csr- 1 hypomorph post-dauer animals, although smaller effects were observed at the spat3 locus, and no significant effects at the K09E9.3 locus (Fig. 4Ciii, iv; Supplemental Fig.S5E,F). From these results, we conclude that CSR-1 may act as an effector to modulate differences in the chromatin state as a result of different developmental histories, and that these chromatin states may spread beyond direct CSR-1 targeted genes.

\section{Small RNA and chromatin states are distinct in dauers}

The altered gene expression and chromatin states in the post-dauers can either be de novo events that occur during dauer exit or a maintained cellular memory that was established during the dauer stage (Hall et al. 2010). Thus, we asked whether sRNA changes observed in post-dauer animals are also observed in dauers, or whether they reflect changes that occur following exit from the dauer stage. We noted that the dauer library was unusual with respect to its endo-siRNA composition. First, the dauer library contained significantly more endo-siRNAs than the larval L3 library, which is unexpected for a developmental stage that lacks a fully developed germline (Fig. 1A; Hubbard and 
Greenstein 2005). We hypothesized that this observation was a result of cloning biases during library construction, although our initial experiments were unable to identify the cause of the bias (see Supplemental text). Second, both the L3 and dauer libraries were enriched for a siRNA class of $23 \mathrm{nt}$ with a $5^{\prime} \mathrm{C}$ as compared with adult libraries (Fig. 5A), suggesting that $\mathrm{L} 3$ and dauer larval stages may express unique siRNA subpopulations.

Mapping of siRNAs to genomic sequences showed that unlike in the adult libraries, siRNAs were clustered at specific locations across examined sequences in the dauer libraries (Fig. 3A). Many of these siRNAs were 22G-RNAs, although a few additional classes were also identified (Fig. 5A; Supplemental Fig. S6A). To test whether changes in siRNA levels in adult animals are "programmed" during early developmental stages, we compared siRNA abundance in dauer and L3 larvae, and in control and post-dauer animals (Supplemental Table S2). We found no obvious correlation such that the sets of either total or 22G-RNAs exhibiting increase or decrease in abundance in post-dauer animals also exhibited increased, decreased, or unaltered expression in dauers as compared with L3 larvae (Supplemental Fig. S6B). Genes with altered siRNA levels in dauer as compared with L3 larvae did not appear to be specifically enriched among the targets of a specific siRNA pathway (Supplemental Fig. S6C).

We next examined levels of histone $\mathrm{H} 3 \mathrm{~K} 4 \mathrm{me} 3$ and H4panAc in dauer larvae using ChIP, followed by qPCR. Our data showed a significant depletion of both H3K4me3 and H4panAc across multiple loci (Fig. 5B), although levels
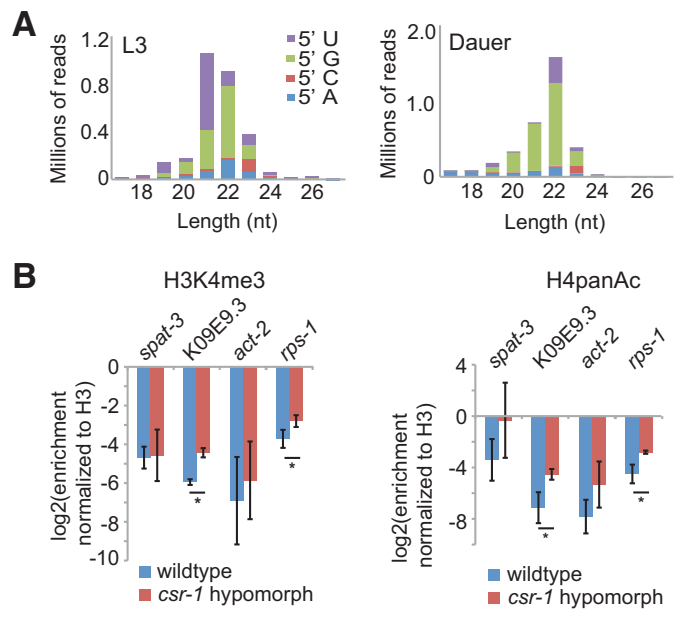

FIGURE 5. Differences in siRNA and chromatin profiles between dauer and L3 larvae. (A) Distribution of endo-siRNAs by nucleotide length and identity of the $5^{\prime}$ nucleotide for dauer and L3 sequenced libraries. Note different $y$-axes in different panels. (B) Log2 enrichment of the indicated histone modifications normalized to histone $\mathrm{H} 3$ in dauer larvae for indicated loci in wild-type and csr-1 hypomorph strains. Error bars represent standard error of the mean. (*) Different from wild type for a given strain at $P<0.05$ via one-way ANOVA and Fisher's LSD post hoc correction for multiple comparisons. Averages are from three technical replicates. of H3 histone appeared to be similar to those in control or post-dauer animals (see Materials and Methods), suggesting that the observed depletion of these modifications were not simply due to experimental difficulties in performing ChIP from dauer samples. Both modifications have previously been identified in the developmentally equivalent L3 larval stage (Christensen et al. 2007; Greer et al. 2010; Li and Kelly 2011; Liu et al. 2011; Xiao et al. 2011). Modification levels were less depleted at some sequences in csr-1 hypomorph dauer animals compared with wild type (Fig. 5B). Together, these results suggest that the dauer stage may reflect a unique siRNA and chromatin state, and that the observed modifications in these examined genes in post-dauer animals are likely to be established upon exit from the dauer stage.

\section{Mutations in siRNA pathway genes affect the expected changes in brood size in post-dauer animals}

We previously showed that post-dauer animals have a significantly larger brood size than control animals, and that this phenotypic plasticity is dependent on a subset of chromatin remodeling genes (Hall et al. 2010). Since siRNA pathways appear to affect gene expression and chromatin state upon passage through the dauer stage, we tested whether mutations in these genes would affect the expected change in brood sizes between control and post-dauer animals. As expected from previous observations, mutations in a subset of these genes (csr-1, mut-16, and rrf-3) resulted in a marked decrease in the number of laid eggs, precluding a firm conclusion of their roles in regulating brood size (Fig. 6; Duchaine et al. 2006; Yigit et al. 2006; Gu et al. 2009). However, the expected increase in progeny number in post-dauer animals was abolished in animals carrying mutations in the ergo- 1 and nrde3 AGO genes, but not in animals mutant for the mago12 worm-specific AGO genes (Fig. 6), suggesting that siRNAmediated pathways regulate critical life history traits as a function of developmental history.

\section{DISCUSSION}

Although wild-type adult C. elegans that have transiently passed through or bypassed the dauer developmental stage appear similar superficially, these populations are marked by a complex and distinct profile of gene expression levels and chromatin signatures as a function of their different developmental trajectories. To determine whether RNAi, a known broadly acting transcriptional and post-transcriptional regulatory mechanism in C. elegans, plays a role in the developmental history-dependent regulation of phenotypic diversity, we conducted a comprehensive sRNA and genetic mutant survey in this specific developmental context. Our study demonstrates that endo-siRNA levels for specific genes can be modulated significantly after passage through the dauer stage. In addition, functional endo-siRNA pathway components are required for changes in gene expression and 


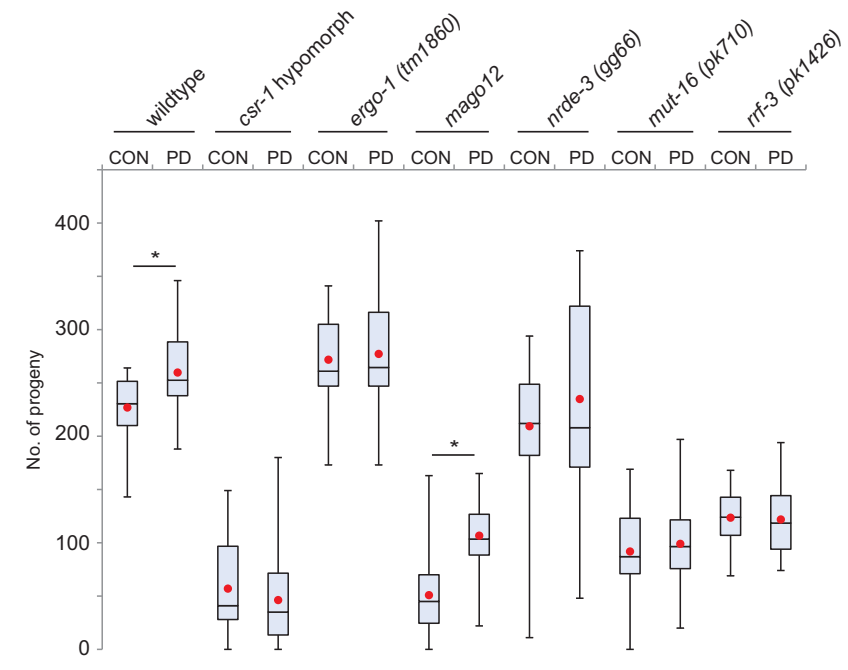

FIGURE 6. Mutations in endo-siRNA pathways affect life history traits. Box-and-whisker plots representing the distribution of total number of progeny produced by control and post-dauer adults in wild-type, and selected 26G- and 22G-RNA pathway mutant strains. The csr-1 strain is a germline rescued strain (Claycomb et al. 2009). Red dots indicate the average, horizontal lines indicate the median, and the top and bottom of the boxes indicate the second and third quartiles. Whiskers indicate maximum and minimum values. $\left(^{*}\right)$ Different from control for a given strain at $P<0.05$ via a two-tailed $t$-test. Averages represent $>20$ worms over two independent trials.

the histone modification code in wild-type post-dauer animals for a subset of genes, and contribute to phenotypic divergence in life history traits. Our results suggest that regulation of RNAi pathways by developmental or environmental experience may mediate adaptive phenotypic plasticity.

\section{The contribution of RNAi pathways in mediating phenotypic plasticity}

A role for RNAi in mediating phenotypic changes in postdauer animals is supported by two observations. First, we found that mutations in specific siRNA pathways alter expected gene expression changes in post-dauer animals. Our initial analyses suggest that multiple siRNA pathways are likely to be involved, since mutations in different siRNA pathways affect different genes expressed in multiple tissue types. These pathways also include both nuclear and cytoplasmic RNA-silencing pathways; CSR-1 has been shown to act in the nucleus (Claycomb et al. 2009), whereas 26G-RNAs act in the cytoplasm (Conine et al. 2010). Thus, distinct developmental trajectories regulate specific siRNA pathways, which may in turn mediate either up- or down-regulation of target genes, perhaps in a tissue-specific manner.

Second, siRNA pathways contribute to the altered postdauer chromatin state. Our data suggest that CSR-1 and perhaps its interacting 22G-RNAs, may in part mediate the decrease in levels of H3K4me3 and H4panAc levels found in wild-type post-dauer animals. In contrast, histone
H3K4me3 and H4panAc levels are dramatically increased at a subset of examined loci in post-dauer $c s r-1$ hypomorph animals, suggesting that CSR-1 is a key effector in modulating chromatin state changes upon passage through the dauer stage. CSR-1 has previously been implicated in regulating chromatin states (Claycomb et al. 2009), and mutations in the CSR-1 pathway have been shown to result in genomewide decreases in $\mathrm{H} 3 \mathrm{~K} 9 \mathrm{me} 2$ levels in the germline (Maine et al. 2005; She et al. 2009). Interestingly, we noted that csr1 mutations affect chromatin modifications at sequences that are not directly predicted to be CSR-1 targets and do not have antisense siRNAs, but that are located within a larger CSR-1-targeted domain. This observation suggests that CSR1-mediated changes in chromatin state may "spread" within a domain, and may affect a larger set of genes than direct CSR1 targets.

Together, these observations point to a complex system of gene expression regulation by both transcriptional and posttranscriptional RNAi mechanisms as a result of passage through the dauer stage. Indeed, a majority of the endosiRNA changes we observe in post-dauer adults compared with control adults are not negatively correlated with changes in gene expression, in contrast to the canonical model of RNAi-mediated post-transcriptional silencing of gene expression in metazoans (Okamura and Lai 2008). However, regulation of gene expression at the transcriptional level of protein-coding genes via modulation of chromatin states via CSR-1 pathways may be considerably more complex, and differs in the type of histone modifications affected compared with the heterochromatin-forming transcriptional gene-silencing mechanism described in fission yeast and plants for centromeric regions (Buhler et al. 2006; Moazed 2009; Kanno and Habu 2011). Recent data indicate a role for sRNA molecules in recruiting chromatin modifiers in C. elegans (Burkhart et al. 2011), and RNAi pathway genes and chromatin modifiers have been shown to regulate the expression of overlapping gene subsets (Grishok et al. 2008; Mansisidor et al. 2011). In addition, gene expression changes may also occur via distinct mechanisms in different tissues. In the future, systematic analyses of transcriptional and post-transcriptional gene expression changes in individual cell types may be important to unravel this complexity (Ooi et al. 2010; Spencer et al. 2011).

\section{A somatic role for RNAi in mediating developmental history-dependent phenotypic plasticity?}

Endo-siRNAs are enriched in the germline and play important roles in maintaining germline integrity (Czech et al. 2008; Gu et al. 2009; Han et al. 2009; Gent et al. 2010). The expression of genes in the GO term category of reproduction is over-represented in the set of genes whose expression is altered in post-dauer animals (Hall et al. 2010), and the majority of these genes appear to be targets of a siRNA pathway (Supplemental Fig. S3A). Moreover, post-dauer 
animals produce a larger number of progeny than control adults (Hall et al. 2010), suggesting a role for germline endo-siRNA pathways in regulating post-dauer phenotypes. However, siRNAs are also found in somatic tissues, and somatic RNAi pathways have been described (Sijen et al. 2001; Simmer et al. 2002; Duchaine et al. 2006; Aoki et al. 2007; Pak and Fire 2007; Gu et al. 2009; Gent et al. 2010; Vasale et al. 2010; Maniar and Fire 2011; Zhang et al. 2011). Several lines of evidence suggest that the observed phenotypes may arise from endo-siRNA-mediated effects in somatic tissues. We noted that all mutant backgrounds in which the increased brood size phenotype is eliminated also affect somatic RNAi, suggesting a somatic contribution to the increased brood size phenotype. In particular, effects on gene expression and chromatin state are observed in csr-1 mutant post-dauer animals that are partially rescued for $c s$ - 1 germline functions, suggesting a somatic role for CSR-1 function in regulating these phenotypes. Moreover, the altered brood size effect does not appear to be inherited, and at least a subset of the altered gene expression patterns is reset in the next generation (SE Hall and P Sengupta, unpubl.). In contrast, longevity and gene expression phenotypes conferred by mutations in chromatin modifier genes have recently been shown to be transmitted to future generations (Greer et al. 2011), and failure to erase germline chromatin marks results in transmission of inappropriate epigenetic information (Katz et al. 2009). Taken together, these observations suggest that somatic RNAi may contribute, at least in part, to the observed gene expression changes and resulting phenotypic plasticity upon dauer passage.

\section{Passage through the dauer stage may prime the genome via RNAi mechanisms for transcriptional flexibility}

The observed decrease in the examined chromatin modifications in wild-type post-dauer animals is largest for the gene set exhibiting highest expression, not all of which exhibit altered expression in post-dauer animals (e.g., act-2 and $r p s-1$ ). Conversely, not all genes exhibiting changes in expression in post-dauer animals show changes in chromatin modification levels (e.g., spat-3). We previously proposed that the altered histone code poises or primes the genome to respond in a differential manner to environmental cues in post-dauer animals (Hall et al. 2010). Although mutations in $c s r-1$ result in depletion of a subset of 22G-RNAs, no changes in gene expression levels were noted, and instead, CSR-1 has been proposed to guide interacting $22 \mathrm{G}-\mathrm{RNAs}$ to their cognate targets to regulate chromatin and chromosome structure (Claycomb et al. 2009). We hypothesize that for a subset of genes, and in particular the highest expressed genes, this priming of their chromatin state in post-dauer animals may similarly be influenced by changes in endo-siRNAs (such as CSR-1-interacting 22G-RNAs) mapping to promoter or coding regions without an immediate change in expression levels. In support of this hypothesis, $45 \%$ of genes with changes in siRNA abundance without changes in gene expression are associated with CSR-1 22G-siRNAs (Supplemental Table S2). This siRNAmediated priming may allow the genome in post-dauers to subsequently respond to encountered stimuli in a manner appropriate to the animal's developmental trajectory.

Post-dauer phenotypes appear to be established following exit from the dauer stage. Dauer larvae exhibit unique patterns of gene expression, siRNA abundance and chromatin state consistent with their unique metabolic and developmental state (Jones et al. 2001; Holt et al. 2002; Wang and Kim 2003; Burnell et al. 2005; Jeong et al. 2009; this work). Specifically, we noted dramatically decreased levels of two highly abundant marks of euchromatin in dauer animals, consistent with decreased transcription during this developmental stage (Snutch and Baillie 1983; Dalley and Golomb 1992). It is also possible that nucleosomes are remodeled in dauers to incorporate alternate histone isoforms, since dauer larvae have been shown to express different histone $\mathrm{H} 1$ isoforms (Jones et al. 2001). Alternatively, dauer larvae may use a distinct histone code. Gene expression patterns have been shown to undergo dramatic changes immediately upon exit from the dauer stage (Dalley and Golomb 1992; Wang and Kim 2003). It is possible that the dramatic remodeling of the gene expression profile, chromatin state, and siRNA abundance in dauer larvae programs the extent and nature of the changes upon exit from the dauer stage and establishes the adult post-dauer profiles.

Phenotypic divergence in an isogenic population provides a template for natural selection mechanisms (Caldji et al. 1998; West-Eberhard 2005; Matesanz et al. 2010; Pfennig et al. 2010). Alternative developmental pathways may be important in generating this phenotypic plasticity; indeed, a recent report indicates that passage through the dauer stage specifies whether a sexually polymorphic nematode will develop as a female or hermaphrodite (Chaudhuri et al. 2011). Endo-siRNAs have now been discovered in many organisms (Okamura and Lai 2008; Ghildiyal and Zamore 2009), although their functions remain to be fully elucidated. Our finding that endo-siRNAs are a component of the pathways that translate developmental experiences into phenotypic changes in C. elegans describes a new role for these small RNA molecules and suggests that these molecules may also represent critical mediators of cellular and organismal plasticity in other organisms.

\section{MATERIALS AND METHODS}

\section{C. elegans strains}

The following strains were used in this study: N2 Bristol; WM193 csr-1(tm892) IV; neIs20 [pie-1::3xFLAG::csr-1+unc-119(+)] (Claycomb et al. 2009); NL1810 mut-16(pk710) I; NL2099 rrf-3 (pk1426) II; and WM191 MAGO12[sago-2(tm894) ppw-1(tm914) ppw-2(tm110) F55A12.1(tm2686) R06C7.1(tm1414) I; Y49F6.1 
(tm1127) ZK1248.7(tm1113) F58G1.1(tm1019) II; C16C10.3 (tm1200) K12B6.1(tm1195) $\quad$ III; T22H9.3(tm1186) V; R04A9.2 (tm1116) X] (Gu et al. 2009).

\section{Growth of control, dauer, and post-dauer animals}

All worms were grown at $20^{\circ} \mathrm{C}$ on standard NGM plates seeded with E. coli OP50. Control and post-dauer adults were grown as previously described (Hall et al. 2010). L3 stage worms were obtained by bleaching gravid adult hermaphrodites and placing eggs on large egg plates (Hall et al. 2010) at a low density. Worms were isolated by sucrose washing once larvae reached the L3 stage. Dauer larvae were grown by placing adult hermaphrodites on small egg plates at a high density so that the progeny entered the dauer stage as a result of high pheromone concentration. After $\sim 60 \mathrm{~h}$, plates were layered with $1 \%$ SDS and incubated for $24 \mathrm{~h}$. Dauer larvae were isolated by sucrose washing.

\section{sRNA library construction and sequencing}

Total RNA was extracted with Trizol reagent (Sigma) from flashfrozen staged worms, and $25 \mu \mathrm{g}$ were subjected to $5^{\prime}$-triphosphate removal treatment with Tobacco Acid Phosphatase (TAP; Epicentre). This treatment left a $5^{\prime}$-monophosphate on siRNAs. Size-selected sRNAs were then subjected to linker ligation reactions and amplification as described previously (Lau et al. 2001). Two biological replicates were sequenced for adult libraries, and one biological replicate for L3 larvae and dauer libraries. Each biological replicate (control and post-dauers \#1 and \#2) underwent library construction and sequencing simultaneously. Thus, comparisons between control and post-dauer libraries are within a biological replicate. sRNA libraries were sequenced on an Illumina GAII machine, yielding between 4 and 14 million reads per library that matched to the C. elegans genome.

\section{Bioinformatics and statistical analyses}

After trimming linker sequences, reads were processed with BowTie (http://bowtie.cbcb.umd.edu) (Langmead et al. 2009) and passed through sequential filters that first partitioned structural RNAs (e.g., ribosomal, transfer, splice leader, and small nucleolar RNAs), and then partitioned known miRNAs (mirBase release 16) (Griffiths-Jones et al. 2008). Remaining reads were mapped to the $C$. elegans reference genome WS190/Ce6 using BowTie, and allowing at most a 1-bp mismatch. RefSeq and Wormbase gene annotation tracks were downloaded from the UCSC Genome Browser and used to count siRNA matches and to display custom genomic plots that were generated via custom $\mathrm{R}$ scripts.

Statistical association analysis was performed on sRNA classes as defined by the major classifications described in Figure 1A, except that transposons and structural RNAs (which comprise only 5\%$8 \%$ of total libraries) were omitted from this analysis due to the ambiguity of assigning sRNAs to each specific repeated entities. Pearson and Spearman Rank correlations were calculated with a one-tailed significance test using SPSS. In the statistical analysis of gene-targeted siRNA changes, a $P$-value for each gene was calculated by the normalized read count of each post-dauer/control pair, based on a $\chi^{2}$ distribution. The composite $P$-value is the multiplication of the two $P$-values by considering the two post-dauer/control biological replicates as independent events.

To determine whether the distribution of genes with both gene expression changes and siRNA level changes were nonrandom, the 872 genes that exhibited significant changes in gene expression between control and post-dauer animals and displayed at least 10 reads per million of siRNAs were examined. These genes were divided into categories based on changes in siRNA levels for up-regulated $(>1.5-$ fold), down-regulated ( $<1.5$-fold), and nonchanging number of siRNAs, and the frequency of each gene being categorized similarly in the two biological replicates was calculated. The observed experiment frequencies and random chance frequencies of these genes were compared using a $\chi^{2}$ goodness-of-fit analysis with the null hypothesis that the observed frequencies arose due to chance.

The following published gene target sets were used for the metaanalyses: wild-type 26G-RNA and alg-3/4 mutant libraries (Conine et al. 2010); CSR-1 immunoprecipitation, csr-1(tm892) mutant and ego-1 (om97) mutant libraries (Claycomb et al. 2009); ERGO-1 immunoprecipitation library (Vasale et al. 2010); mago12 mutant library (Gu et al. 2009); mut-16(pk710) mutant library (Zhang et al. 2011) and NRDE-3 immunoprecipitation library (Guang et al. 2008).

\section{qRT-PCR}

Total RNA from control and post-dauer animals from two biological replicates of wild-type and mutant strains was extracted using Trizol reagent (Sigma). WM193 and NL1810 strains exhibit dauer entry defects in the presence of high pheromone concentrations (data not shown); thus, dauers were collected by washing plates with $1 \%$ SDS that were incubated at $20^{\circ} \mathrm{C}$ until food was depleted and animals were starved. Total RNA was treated with DNaseI (NEB), and reverse transcribed using Superscript III according to manufacturer's protocol (Invitrogen). Quantitative PCR was performed as described previously (Hall et al. 2010). Each reaction was performed independently in triplicate, using each biological replicate at least once. Experimental gene expression levels were normalized to the expression of ifd-2. Ratios of post-dauer to control gene expression were calculated using the $\log 2$ transformed data, and standard deviations were propagated from the raw data to the average before converting to SEM. Significance was determined using a one-way ANOVA and LSD posthoc test.

\section{ChIP and qPCR}

Chromatin immunoprecipitation was performed using $\sim 100 \mu \mathrm{L}$ of staged control, post-dauer, and dauer animals. Formaldehyde fixation and lysate preparation was performed as described previously (Chu et al. 2002). Immunoprecipitation was performed using the manufacturer's protocol (Upstate) using $5 \mu \mathrm{L}$ of each antibody: anti-histone H3 (Abcam \#ab1791), anti-histone H3K4me3 (Upstate \#07-473), and anti-histone H4 panAcetyl (Upstate \#06598). Three nanograms of immunoprecipitated DNA was used for each qPCR reaction using a protocol described previously (Hall et al. 2010). For each gene, enrichment values for each histone modification were normalized to histone $\mathrm{H} 3$ values (Ct values ranged from $\sim 20$ to 30 ). Significance was determined using a oneway ANOVA with LSD post hoc test. Primer sequences are available upon request. 


\section{Brood size analyses}

Brood size measurements were performed as previously described (Hall et al. 2010). Individual L4 stage worms were moved to single plates containing E. coli OP50. Each day adult worms were transferred to fresh plates and the number of hatched progeny were counted. Worms that died, exploded, or crawled off the plate during the experiment were censored. Significance between control and post-dauer brood sizes was determined using a $t$-test.

\section{DATA DEPOSITION}

All primary sequencing data from this study have been deposited at the Gene Expression Omnibus at NCBI under series GSE33313.

\section{SUPPLEMENTAL MATERIAL}

Supplemental material is available for this article.

\section{ACKNOWLEDGMENTS}

We are grateful to Matt Beverly for assistance with bioinformatics analyses, Harry Bell for technical support, Jessica Matts for assistance with library construction, Sadanand Vodala and Joe Rodriguez for assistance with sequencing, Michael Rosbash for access to the Illumina GAII sequencer, the Caenorhabditis Genetics Center and Shohei Mitani (National BioResource Project, Japan) for strains, the Sengupta lab for discussion and advice, and Julie Claycomb, Craig Hunter, and Eleanor Maine for critical comments on the manuscript. This work was supported by the National Science Foundation (IOS 0842452 to P.S.) and the National Institutes of Health (Core Facilities Grant P30 NS045713 to the Brandeis Biology Department and R00HD057298 to N.C.L.). N.C.L. is a Searle Scholar.

Received September 14, 2012; accepted November 26, 2012.

\section{REFERENCES}

Aoki K, Moriguchi H, Yoshioka T, Okawa K, Tabara H. 2007. In vitro analyses of the production and activity of secondary small interfering RNAs in C. elegans. EMBO J 26: 5007-5019.

Ashe A, Sapetschnig A, Weick EM, Mitchell J, Bagijn MP, Cording AC, Doebley AL, Goldstein LD, Lehrbach NJ, Le Pen J, et al. 2012. piRNAs can trigger a multigenerational epigenetic memory in the germline of C. elegans. Cell 150: 88-99.

Bagijn MP, Goldstein LD, Sapetschnig A, Weick EM, Bouasker S, Lehrbach NJ, Simard MJ, Miska EA. 2012. Function, targets, and evolution of Caenorhabditis elegans piRNAs. Science 337: 574-578.

Bale TL, Baram TZ, Brown AS, Goldstein JM, Insel TR, McCarthy MM, Nemeroff CB, Reyes TM, Simerly RB, Susser ES, et al. 2010. Early life programming and neurodevelopmental disorders. Biol Psychiatry 68: $314-319$.

Bartel DP. 2009. MicroRNAs: Target recognition and regulatory functions. Cell 136: 215-233.

Batista PJ, Ruby JG, Claycomb JM, Chiang R, Fahlgren N, Kasschau KD, Chaves DA, Gu W, Vasale JJ, Duan S, et al. 2008. PRG-1 and 21URNAs interact to form the piRNA complex required for fertility in C. elegans. Mol Cell 31: 67-78.

Billi AC, Alessi AF, Khivansara V, Han T, Freeberg M, Mitani S, Kim JK. 2012. The Caenorhabditis elegans HEN1 ortholog, HENN-1, methylates and stabilizes select subclasses of germline small RNAs. PLoS Genet 8: e1002617.
Boisvert ME, Simard MJ. 2008. RNAi pathway in C. elegans: The argonautes and collaborators. Curr Top Microbiol Immunol 320: 21-36.

Bourc'his D, Voinnet O. 2010. A small-RNA perspective on gametogenesis, fertilization, and early zygotic development. Science 330: 617-622.

Brodersen P, Voinnet O. 2009. Revisiting the principles of microRNA target recognition and mode of action. Nat Rev Mol Cell Biol 10: $141-148$.

Buhler M, Verdel A, Moazed D. 2006. Tethering RITS to a nascent transcript initiates RNAi- and heterochromatin-dependent gene silencing. Cell 125: 873-886.

Burkhart KB, Guang S, Buckley BA, Wong L, Bochner AF, Kennedy S. 2011. A pre-mRNA-associating factor links endogenous siRNAs to chromatin regulation. PLoS Genet 7: e1002249.

Burnell AM, Houthoofd K, O'Hanlon K, Vanfleteren JR. 2005. Alternate metabolism during the dauer stage of the nematode Caenorhabditis elegans. Exp Gerontol 40: 850-856.

Caldji C, Tannenbaum B, Sharma S, Francis D, Plotsky PM, Meaney MJ. 1998. Maternal care during infancy regulates the development of neural systems mediating the expression of fearfulness in the rat. Proc Natl Acad Sci 95: 5335-5340.

Caldji C, Hellstrom IC, Zhang TY, Diorio J, Meaney MJ. 2011. Environmental regulation of the neural epigenome. FEBS Lett 585: 2049-2058.

Carthew RW, Sontheimer EJ. 2009. Origins and mechanisms of miRNAs and siRNAs. Cell 136: 642-655.

Chaudhuri J, Kache V, Pires-daSilva A. 2011. Regulation of sexual plasticity in a nematode that produces males, females, and hermaphrodites. Curr Biol 21: 1548-1551.

Christensen J, Agger K, Cloos PA, Pasini D, Rose S, Sennels L, Rappsilber J, Hansen KH, Salcini AE, Helin K. 2007. RBP2 belongs to a family of demethylases, specific for tri- and dimethylated lysine 4 on histone 3. Cell 128: 1063-1076.

Chu DS, Dawes HE, Lieb JD, Chan RC, Kuo AF, Meyer BJ. 2002. A molecular link between gene-specific and chromosome-wide transcriptional repression. Genes Dev 16: 796-805.

Claycomb JM, Batista PJ, Pang KM, Gu W, Vasale JJ, van Wolfswinkel JC, Chaves DA, Shirayama M, Mitani S, Ketting RF, et al. 2009. The Argonaute CSR-1 and its 22G-RNA cofactors are required for holocentric chromosome segregation. Cell 139: 123-134.

Conine CC, Batista PJ, Gu W, Claycomb JM, Chaves DA, Shirayama M, Mello CC. 2010. Argonautes ALG-3 and ALG-4 are required for spermatogenesis-specific 26G-RNAs and thermotolerant sperm in Caenorhabditis elegans. Proc Natl Acad Sci 107: 3588-3593.

Czech B, Malone CD, Zhou R, Stark A, Schlingeheyde C, Dus M, Perrimon N, Kellis M, Wohlschlegel JA, Sachidanandam R, et al. 2008. An endogenous small interfering RNA pathway in Drosophila. Nature 453: 798-802.

Dalley BK, Golomb M. 1992. Gene expression in the Caenorhabditis elegans dauer larva: Developmental regulation of Hsp90 and other genes. Dev Biol 151: 80-90.

Das PP, Bagijn MP, Goldstein LD, Woolford JR, Lehrbach NJ, Sapetschnig A, Buhecha HR, Gilchrist MJ, Howe KL, Stark R, et al. 2008. Piwi and piRNAs act upstream of an endogenous siRNA pathway to suppress Tc3 transposon mobility in the Caenorhabditis elegans germline. Mol Cell 31: 79-90.

Duchaine TF, Wohlschlegel JA, Kennedy S, Bei Y, Conte D Jr, Pang K, Brownell DR, Harding S, Mitani S, Ruvkun G, et al. 2006. Functional proteomics reveals the biochemical niche of C. elegans DCR-1 in multiple small-RNA-mediated pathways. Cell 124: 343-354.

Ebrahimi CM, Rankin CH. 2007. Early patterned stimulation leads to changes in adult behavior and gene expression in C. elegans. Genes Brain Behav 6: 517-528.

Fernandez-Twinn DS, Ozanne SE. 2010. Early life nutrition and metabolic programming. Ann N Y Acad Sci 1212: 78-96.

Fischer SE. 2010. Small RNA-mediated gene silencing pathways in $C$. elegans. Int J Biochem Cell Biol 42: 1306-1315.

Fischer SE, Montgomery TA, Zhang C, Fahlgren N, Breen PC, Hwang A, Sullivan CM, Carrington JC, Ruvkun G. 2011. The ERI-6/7 helicase 
acts at the first stage of an siRNA amplification pathway that targets recent gene duplications. PLoS Genet 7: e1002369.

Gent JI, Lamm AT, Pavelec DM, Maniar JM, Parameswaran P, Tao L, Kennedy S, Fire AZ. 2010. Distinct phases of siRNA synthesis in an endogenous RNAi pathway in C. elegans soma. Mol Cell 37: 679-689.

Ghildiyal M, Zamore PD. 2009. Small silencing RNAs: An expanding universe. Nat Rev Genet 10: 94-108.

Ghildiyal M, Seitz H, Horwich MD, Li C, Du T, Lee S, Xu J, Kittler EL, Zapp ML, Weng Z, et al. 2008. Endogenous siRNAs derived from transposons and mRNAs in Drosophila somatic cells. Science 320: 1077-1081.

Golden JW, Riddle DL. 1982. A pheromone influences larval development in the nematode Caenorhabditis elegans. Science 218: 578-580.

Golden JW, Riddle DL. 1984. The Caenorhabditis elegans dauer larva: Developmental effects of pheromone, food, and temperature. Dev Biol 102: 368-378.

Greer EL, Maures TJ, Hauswirth AG, Green EM, Leeman DS, Maro GS, Han S, Banko MR, Gozani O, Brunet A. 2010. Members of the H3K4 trimethylation complex regulate lifespan in a germline-dependent manner in C. elegans. Nature 466: 383-387.

Greer EL, Maures TJ, Ucar D, Hauswirth AG, Mancini E, Lim JP, Benayoun BA, Shi Y, Brunet A. 2011. Transgenerational epigenetic inheritance of longevity in Caenorhabditis elegans. Nature 479:365-371.

Grewal SI. 2010. RNAi-dependent formation of heterochromatin and its diverse functions. Curr Opin Genet Dev 20: 134-141.

Griffiths-Jones S, Saini HK, van Dongen S, Enright AJ. 2008. miRBase: Tools for microRNA genomics. Nucleic Acids Res 36 (Database issue): D154-D158

Grishok A, Hoersch S, Sharp PA. 2008. RNA interference and retinoblastoma-related genes are required for repression of endogenous siRNA targets in Caenorhabditis elegans. Proc Natl Acad Sci 105: 20386-20391.

Gu W, Shirayama M, Conte D Jr, Vasale J, Batista PJ, Claycomb JM, Moresco JJ, Youngman EM, Keys J, Stoltz MJ, et al. 2009. Distinct argonaute-mediated 22G-RNA pathways direct genome surveillance in the C. elegans germline. Mol Cell 36: 231-244.

Guang S, Bochner AF, Pavelec DM, Burkhart KB, Harding S, Lachowiec J, Kennedy S. 2008. An Argonaute transports siRNAs from the cytoplasm to the nucleus. Science 321: 537-541.

Guang S, Bochner AF, Burkhart KB, Burton N, Pavelec DM, Kennedy S. 2010. Small regulatory RNAs inhibit RNA polymerase II during the elongation phase of transcription. Nature 465: 1097-1101.

Hall SE, Beverly M, Russ C, Nusbaum C, Sengupta P. 2010. A cellular memory of developmental history generates phenotypic diversity in C. elegans. Curr Biol 20: 149-155.

Han T, Manoharan AP, Harkins TT, Bouffard P, Fitzpatrick C, Chu DS, Thierry-Mieg D, Thierry-Mieg J, Kim JK. 2009. 26G endo-siRNAs regulate spermatogenic and zygotic gene expression in Caenorhabditis elegans. Proc Natl Acad Sci 106: 18674-18679.

Harvey SC, Orbidans HE. 2011. All eggs are not equal: The maternal environment affects progeny reproduction and developmental fate in Caenorhabditis elegans. PLoS One 6: e25840.

Holt SJ, Cress WA, Van Staden J. 2002. Evidence for dynamic alteration in histone gene clusters of Caenorhabditis elegans: A topoisomerase II connection? Genet Res 79: 11-22.

Hubbard EJ, Greenstein D. 2005. Introduction to the germ line. In WormBook (ed. The C. elegans Research Community), pp. 1-4. doi: 10.1895/wormbook.1.7.1, http://www.wormbook.org.

Jeong PY, Kwon MS, Joo HJ, Paik YK. 2009. Molecular time-course and the metabolic basis of entry into dauer in Caenorhabditis elegans. PLoS One 4: e4162.

Jones SJ, Riddle DL, Pouzyrev AT, Velculescu VE, Hillier L, Eddy SR, Stricklin SL, Baillie DL, Waterston R, Marra MA. 2001. Changes in gene expression associated with developmental arrest and longevity in Caenorhabditis elegans. Genome Res 11: 1346-1352.

Kanno T, Habu Y. 2011. siRNA-mediated chromatin maintenance and its function in Arabidopsis thaliana. Biochim Biophys Acta 1809: 444-451.
Karp X, Hammell M, Ow MC, Ambros V. 2011. Effect of life history on microRNA expression during C. elegans development. RNA 17: 639-651.

Katz DJ, Edwards TM, Reinke V, Kelly WG. 2009. A C. elegans LSD1 demethylase contributes to germline immortality by reprogramming epigenetic memory. Cell 137: 308-320.

Kawamura Y, Saito K, Kin T, Ono Y, Asai K, Sunohara T, Okada TN, Siomi MC, Siomi H. 2008. Drosophila endogenous small RNAs bind to Argonaute 2 in somatic cells. Nature 453: 793-797.

Ketting RF. 2011. microRNA biogenesis and function: An overview. $A d v$ Exp Med Biol 700: 1-14.

Langmead B, Trapnell C, Pop M, Salzberg SL. 2009. Ultrafast and memory-efficient alignment of short DNA sequences to the human genome. Genome Biol 10: R25.

Lau NC, Lim LP, Weinstein EG, Bartel DP. 2001. An abundant class of tiny RNAs with probable regulatory roles in Caenorhabditis elegans. Science 294: 858-862.

Lee RC, Hammell CM, Ambros V. 2006. Interacting endogenous and exogenous RNAi pathways in Caenorhabditis elegans. RNA 12: 589-597.

Lejeune E, Allshire RC. 2011. Common ground: Small RNA programming and chromatin modifications. Curr Opin Cell Biol 23: 258-265.

Li T, Kelly WG. 2011. A role for Set1/MLL-related components in epigenetic regulation of the Caenorhabditis elegans germ line. PLoS Genet 7: e1001349.

Liu T, Rechtsteiner A, Egelhofer TA, Vielle A, Latorre I, Cheung MS, Ercan S, Ikegami K, Jensen M, Kolasinska-Zwierz P, et al. 2011. Broad chromosomal domains of histone modification patterns in C. elegans. Genome Res 21: 227-236.

Maine EM, Hauth J, Ratliff T, Vought VE, She X, Kelly WG. 2005. EGO1 , a putative RNA-dependent RNA polymerase, is required for heterochromatin assembly on unpaired DNA during C. elegans meiosis. Curr Biol 15: 1972-1978.

Maniar JM, Fire AZ. 2011. EGO-1, a C. elegans RdRP, modulates gene expression via production of mRNA-templated short antisense RNAs. Curr Biol 21: 449-459.

Mansisidor AR, Cecere G, Hoersch S, Jensen MB, Kawli T, Kennedy LM, Chavez V, Tan MW, Lieb JD, Grishok A. 2011. A conserved PHD finger protein and endogenous RNAi modulate insulin signaling in Caenorhabditis elegans. PLoS Genet 7: e1002299.

Matesanz S, Gianoli E, Valladares F. 2010. Global change and the evolution of phenotypic plasticity in plants. Ann N Y Acad Sci 1206: $35-55$.

Moazed D. 2009. Small RNAs in transcriptional gene silencing and genome defence. Nature 457: 413-420.

Montgomery TA, Rim YS, Zhang C, Dowen RH, Phillips CM, Fischer SE, Ruvkun G. 2012. PIWI associated siRNAs and piRNAs specifically require the Caenorhabditis elegans HEN1 ortholog henn-1. PLoS Genet 8: e1002616.

Okamura K, Lai EC. 2008. Endogenous small interfering RNAs in animals. Nat Rev Mol Cell Biol 9: 673-678.

Ooi SL, Henikoff JG, Henikoff S. 2010. A native chromatin purification system for epigenomic profiling in Caenorhabditis elegans. Nucleic Acids Res 38: e26.

Pak J, Fire A. 2007. Distinct populations of primary and secondary effectors during RNAi in C. elegans. Science 315: 241-244.

Pfennig DW, Wund MA, Snell-Rood EC, Cruickshank T, Schlichting CD, Moczek AP. 2010. Phenotypic plasticity's impacts on diversification and speciation. Trends Ecol Evol 25: 459-467.

Remy JJ. 2010. Stable inheritance of an acquired behavior in Caenorhabditis elegans. Curr Biol 20: R877-R878.

Rinaudo P, Wang E. 2012. Fetal programming and metabolic syndrome. Annu Rev Physiol 74: 107-130.

Rose JK, Sangha S, Rai S, Norman KR, Rankin CH. 2005. Decreased sensory stimulation reduces behavioral responding, retards development, and alters neuronal connectivity in Caenorhabditis elegans. $J$ Neurosci 25: 7159-7168.

Ruby T, Whittaker C, Withers DR, Chelbi-Alix MK, Morin V, Oudin A, Young JR, Zoorob R. 2006. Transcriptional profiling reveals a 
possible role for the timing of the inflammatory response in determining susceptibility to a viral infection. J Virol 80: 9207-9216.

She X, Xu X, Fedotov A, Kelly WG, Maine EM. 2009. Regulation of heterochromatin assembly on unpaired chromosomes during Caenorhabditis elegans meiosis by components of a small RNA-mediated pathway. PLoS Genet 5: e1000624.

Shirayama M, Seth M, Lee HC, Gu W, Ishidate T, Conte D Jr, Mello CC. 2012. piRNAs Initiate an epigenetic memory of nonself RNA in the C. elegans germline. Cell 150: 65-77.

Sijen T, Fleenor J, Simmer F, Thijssen KL, Parrish S, Timmons L, Plasterk RH, Fire A. 2001. On the role of RNA amplification in dsRNA-triggered gene silencing. Cell 107: 465-476.

Simmer F, Tijsterman M, Parrish S, Koushika SP, Nonet ML, Fire A, Ahringer J, Plasterk RH. 2002. Loss of the putative RNA-directed RNA polymerase RRF-3 makes C. elegans hypersensitive to RNAi. Curr Biol 12: 1317-1319.

Snutch TP, Baillie DL. 1983. Alterations in the pattern of gene expression following heat shock in the nematode Caenorhabditis elegans. Can J Biochem Cell Biol 61: 480-487.

Spencer WC, Zeller G, Watson JD, Henz SR, Watkins KL, McWhirter RD, Petersen S, Sreedharan VT, Widmer C, Jo J, et al. 2011. A spatial and temporal map of C. elegans gene expression. Genome Res 21: 325-341.

Tam LC, Kiang AS, Kennan A, Kenna PF, Chadderton N, Ader M, Palfi A, Aherne A, Ayuso C, Campbell M, et al. 2008. Therapeutic benefit derived from RNAi-mediated ablation of IMPDH1 transcripts in a murine model of autosomal dominant retinitis pigmentosa (RP10). Hum Mol Genet 17: 2084-2100.

Tamashiro KL, Moran TH. 2010. Perinatal environment and its influences on metabolic programming of offspring. Physiol Behav 100: 560-566.

van Wolfswinkel JC, Ketting RF. 2010. The role of small non-coding RNAs in genome stability and chromatin organization. J Cell Sci 123: $1825-1839$. van Wolfswinkel JC, Claycomb JM, Batista PJ, Mello CC, Berezikov E, Ketting RF. 2009. CDE-1 affects chromosome segregation through uridylation of CSR-1-bound siRNAs. Cell 139: 135-148.

Vasale JJ, Gu W, Thivierge C, Batista PJ, Claycomb JM, Youngman EM, Duchaine TF, Mello CC, Conte D Jr. 2010. Sequential rounds of RNA-dependent RNA transcription drive endogenous small-RNA biogenesis in the ERGO-1/Argonaute pathway. Proc Natl Acad Sci 107: 3582-3587.

Wang J, Kim SK. 2003. Global analysis of dauer gene expression in Caenorhabditis elegans. Development 130: 1621-1634.

Wang G, Reinke V. 2008. A C. elegans Piwi, PRG-1, regulates 21U-RNAs during spermatogenesis. Curr Biol 18: 861-867.

Watanabe T, Totoki Y, Toyoda A, Kaneda M, Kuramochi-Miyagawa S, Obata Y, Chiba H, Kohara Y, Kono T, Nakano T, et al. 2008. Endogenous siRNAs from naturally formed dsRNAs regulate transcripts in mouse oocytes. Nature 453: 539-543.

Weaver IC, Cervoni N, Champagne FA, D'Alessio AC, Sharma S, Seckl JR, Dymov S, Szyf M, Meaney MJ. 2004. Epigenetic programming by maternal behavior. Nat Neurosci 7: 847-854.

West-Eberhard MJ. 2005. Developmental plasticity and the origin of species differences. Proc Natl Acad Sci 102 (Suppl 1): 6543-6549.

Xiao Y, Bedet C, Robert VJ, Simonet T, Dunkelbarger S, Rakotomalala C, Soete G, Korswagen HC, Strome S, Palladino F. 2011. Caenorhabditis elegans chromatin-associated proteins SET-2 and ASH-2 are differentially required for histone H3 Lys 4 methylation in embryos and adult germ cells. Proc Natl Acad Sci 108: 8305-8310.

Yigit E, Batista PJ, Bei Y, Pang KM, Chen CC, Tolia NH, Joshua-Tor L, Mitani S, Simard MJ, Mello CC. 2006. Analysis of the C. elegans Argonaute family reveals that distinct Argonautes act sequentially during RNAi. Cell 127: 747-757.

Zhang C, Montgomery TA, Gabel HW, Fischer SE, Phillips CM, Fahlgren N, Sullivan CM, Carrington JC, Ruvkun G. 2011. mut-16 and other mutator class genes modulate $22 \mathrm{G}$ and $26 \mathrm{G}$ siRNA pathways in Caenorhabditis elegans. Proc Natl Acad Sci 108: 1201-1208. 

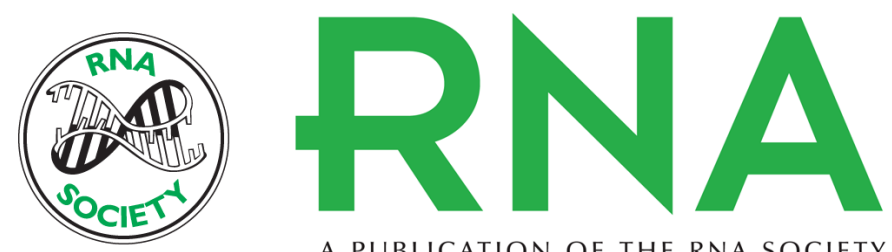

A PUBLICATION OF THE RNA SOCIETY

\section{RNAi pathways contribute to developmental history-dependent phenotypic plasticity in C. elegans}

Sarah E. Hall, Gung-Wei Chirn, Nelson C. Lau, et al.

RNA 2013 19: 306-319 originally published online January 17, 2013

Access the most recent version at doi:10.1261/rna.036418.112

\section{Supplemental http://rnajournal.cshlp.org/content/suppl/2012/12/27/rna.036418.112.DC1 \\ Material}

References This article cites 93 articles, 25 of which can be accessed free at:

http://rnajournal.cshlp.org/content/19/3/306.full.html\#ref-list-1

\section{License}

Email Alerting Receive free email alerts when new articles cite this article - sign up in the box at the Service top right corner of the article or click here.

\section{|II!"II Providing Precise Solutions tor your research.}

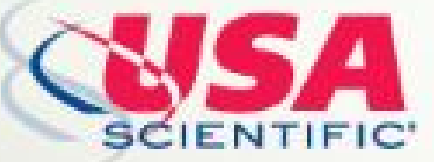

To subscribe to $R N A$ go to:

http://rnajournal.cshlp.org/subscriptions 